\title{
OCORRÊNCIA DE Escherichia coli 0157:H7 EM VEGETAIS E RESISTÊNCIA AOS AGENTES DE DESINFECÇÃO DE VERDURAS ${ }^{1}$
}

\author{
Neusely da SILVA ${ }^{2, *}$, Neliane Ferraz de Arruda SILVEIRA², \\ Fumio YOKOYA ${ }^{3}$, Margarete Midori OKAZAKI ${ }^{2}$
}

\section{RESUMO}

Foi feito um estudo da ocorrência de E.coli O157:H7 em vegetais que são normalmente consumidos crus no Brasil e uma avaliação da sua resistência aos sanitizantes disponiveis no mercado para desinfecção de verduras, equipamentos e utensílios, incluindo compostos clorados e compostos de amônio quaternário. Na avaliação da ocorrência em vegetais foram analisadas 869 amostras, não sendo detectada a presença do patógeno. Os imunoensaios enzimáticos (ELISA) utilizados nas análises (Reveal E.coli O157 Neogem e EHEC Test Kit 3M Company) apresentaram uma taxa de falsos resultados presuntivos de 13,6 e 11,8\%, respectivamente, não confirmados como E.coli O157 nos testes bioquimicos posteriores. Na avaliação da resistência aos sanitizantes pelo método 960.9 da AOAC, observou-se que os tratamentos com 100 e 200ppm de hipoclorito de sódio, dicloroisocianurato de sódio e cloreto de benzalcônio/30s se mostraram eficazes contra E.coli ATCC 11229 e E.coli O157:H7 ATCC 43890, promovendo mais de 5 reduções decimais nas populações alvo.

Palavras-chave: Escherichia coli O157:H7; ocorrência; vegetais; desinfecção; cloro; amônio quaternário; hipoclorito de sódio; dicloroisocianurato de sódio; cloreto de banzalcônio.
\end{abstract}

\section{SUMMARY}

OCCURRENCE OF Escherichia coli 0157:H7 IN VEGETABLES AND ITS RESISTANCE TO THE DISINFECTANTS USED IN FRESH PRODUCE. A study of E.coli O157:H7 occurrence in vegetables that are usually consumed raw in Brazil was carried out as well as an evaluation of its resistance to the sanitizers available on the market for disinfection of green vegetables, equipment and utensils, including chlorine and quaternary ammonium compounds. In the evaluation of the occurrence in vegetables, 869 samples were analyzed, without the presence of the pathogen being detected. The enzymatic immunoassay (ELISA) used in the analyses (Reveal E.coli O157 Neogem e EHEC Test Kit 3M Company) presented a false presumtive rate of 13,6 and 11,8\%, respectively, not confirmed as E.coli O157 in the subsequent stages of identification. In the evaluation of the resistance to the sanitizers using the AOAC method 960.9 it was observed that the treatment with $100 \mathrm{ppm}$ and $200 \mathrm{ppm}$ of sodium hypochlorite, sodium dichloroisocyanurate and benzalconium chloride/30s showed effectiveness against E.coli ATCC 11229 e E.coli O157:H7 ATCC 43890, with more than 5 decimal reductions over the population. Keywords: Escherichia coli O157:H7; occurrence; vegetables; disinfection; chlorine; quaternary ammonium; sodium hypochlorite; sodium dichloroisocyanurate, benzalconium chloride.

\section{1 - INTRODUÇÃO}

Escherichia coli é um habitante normal do trato-intestinal dos animais (incluindo o homem) e exerce um efeito benéfico sobre o organismo, suprimindo a multiplicação de bactérias prejudiciais e sintetizando uma considerável quantidade de vitaminas. Dentre as cepas de E.coli, entretanto, há um grupo capaz de provocar doenças em indivíduos humanos, coletivamente chamadas de E.coli enteropatogênicas (EEC). Essas cepas ocupam hoje o segundo lugar entre os principais agentes doenças de origem alimentar nos Estados Unidos, onde responderam por $7,4 \%$ dos surtos e $28,6 \%$ das mortes provocadas por bactérias naquele país, no período de 1993 a 1997 [34].

Atualmente há seis classes de E.coli enteropatogênicas reconhecidas, dentre elas as cepas de E.coli O157:H7, que pertencem ao grupo das E.coli enterohemorrágicas (EHEC) ou produtoras de verotoxina (VTEC). A patogenicidade das cepas EHEC parece estar associada a uma série de fatores, incluindo a produção de várias citotoxinas, coletivamente chamadas de

\footnotetext{
Recebido para publicação em 01/06/2001. Aceito para publicação em 17/10/2002 (000668).

2. Instituto de Tecnologia de Alimentos (ITAL), Núcleo de Microbilogia, Av. Brasil, 2880, CEP 13473-001 - Campinas (SP). E-mail: neusely@ital.org.br 3. Faculdade de Engenharia de Alimentos, Universidade Estadual de Campinas (UNICAMP).

* A quem a correspondência deve ser enviada.
}

verotoxinas (VTs) ou "shiga-like" toxinas (SLTs), similares à toxina produzida pela bactéria Shigella dysenteriae tipo I $[19,44]$. As VTs provocam uma doença chamada de colite hemorrágica que, em casos mais graves, resulta em um quadro conhecido como sindrome urêmica hemolitica (HUS) [30]. A colite hemorrágica tem um período de incubação de 3 a 10 dias e duração de 2 a 9 dias. Os sintomas são diarréia sanguinolenta e dores abdominais severas e, de acordo com a literatura, cerca de $10-15 \%$ dos casos agravam-se até o quadro de HUS [18], situação em que ocorre destruição de eritrócitos e falha aguda dos rins, levando à necessidade de diálise, transplante dos rins ou morte $[43,44]$. A dose infectiva é ainda desconhecida mas, através da compilação de dados de surtos investigados nos Estados Unidos, parece encontrar-se na faixa de 10 células por grama ou mililitro do alimento consumido [18].

O grupo EHEC tem mais de 60 sorótipos que produzem SLT, porém, de acordo com KARMALI [25], o sorótipo O157:H7 predomina, sendo o mais freqüentemente associado a surtos de colite hemorrágica e HUS. As principais caracteristicas que distinguem E.coli O157:H7 das demais cepas de E.coli são o crescimento pobre ou nulo a $44^{\circ} \mathrm{C}$ e a incapacidade de utilizar o sorbitol e produzir a enzima $\beta$-glicuronidase $[28,30$, $32,38]$. Em função dessas diferenças, não são detectadas nas análises de coliformes fecais pelo método do número mais provável (NMP), que utiliza a fermentação da lactose a $44,5^{\circ} \mathrm{C}$ como característica confirmativa, 
nem nas análises diretas de E.coli utilizando substratos para a enzima $\beta$-glicuronidase.

\section{1 - Alimentos envolvidos em surtos}

Nos Estados Unidos, de acordo com os dados do CDC (Center for Disease Control and Prevention) [34], os alimentos mais freqüentemente implicados em surtos provocados por cepas de E.coli enteropatogênica, no período de 1993 a 1997, foram a carne bovina (25\%) e as frutas, vegetais e saladas (20\%). A US Food and Drug Administration [18] acredita que dentre as cepas enteropatogênicas envolvidas, E.coli O157:H7 seja a mais freqüente, representando hoje o segundo agente etiológico de diarréia bacteriana nos Estados da costa do Pacífico.

E.coli O157:H7 foi implicada pela primeira vez em surto de doença de origem alimentar em 1982 e, nos anos seguintes, mais de 30 surtos foram registrados só nos Estados Unidos [21]. Em 1993 um grande surto envolvendo mais de 700 pessoas atingiu 4 estados norte americanos, com 51 casos de HUS e 4 mortes. O surto foi provocado pelo consumo de hambúrguer mal cozido em uma rede regional de restaurantes tipo "fast food", chamando a atenção para a carne como fonte potencial desse microrganismo. A partir daí as pesquisas demonstraram que o trato-intestinal de ruminantes, particularmente bovinos e ovinos, parece ser o principal reservatório das cepas entero-hemorrágicas de E.coli O157:H7 [26]. Nesse tipo de animais, a incidência em fezes varia de 0 a $10 \%$ [15] e a carne bovina moída (hambúrguer), de maneira especial, tem sido o principal agente de surtos registrados nos Estados Unidos [18, 19] e países da Europa.

Nos últimos 10 anos, entretanto, aumentou significativamente o número de surtos associados com outros veículos além da carne, particularmente as frutas, os sucos de frutas, os vegetais e as saladas preparadas com vegetais. Em 1991 ocorreu um surto nos Estados Unidos em que 23 pessoas foram atingidas através do consumo de cidra de maçã não pasteurizada [19]. Aparentemente, a cidra foi produzida com maçãs recolhidas do chão e contaminadas com esterco de bovinos.

Em 1993 ocorreu um surto no Estado do Oregon, EUA, provocado pelo consumo de melões e outros itens da mesa de saladas de um restaurante, aparentemente atingidos por contaminação cruzada através de produtos cárneos manipulados na cozinha [19].

Em 1995, 92 pessoas foram atingidas por um surto em Montana, EUA, provocado pelo consumo de alface contaminada com água de irrigação [3].

Em 1996 ocorreram dois surtos nos Estados Unidos, provocados pelo consumo de suco de maçã não pasteurizado. O primeiro atingiu pelo menos 70 pessoas, espalhadas por vários estados do oeste, com 3 casos de HUS e 1 morte [10]. O segundo atingiu 45 pessoas dos estados da California, Colorado, Columbia Britânica e Washington, com 12 casos de HUS e nenhuma morte [9].

Em 1996 também foram registrados 4 surtos em escolas primárias do Japão, envolvendo o consumo de sa- ladas [2]. O maior deles ocorreu na cidade de Sakai, com mais de 5.500 pessoas atingidas pelo consumo de broto de rabanete, com 3 mortes registradas. Os demais ocorreram nas cidades de Gifu, com 379 pessoas atingidas pelo consumo de salada, Morioka, com 47 atingidos pelo consumo de salada e frutos do mar e Obihiro, com 157 atingidos também pelo consumo de salada.

Em 1997 ocorreram dois surtos nos Estados Unidos, provocados pelo consumo de broto de alfafa [11], um no estado de Michigan, com 60 pessoas atingidas (2 casos de HUS) e outro no Estado da Virginia, com 48 pessoas atingidas e nenhum caso de HUS. Em 2000, novamente nos Estados Unidos, mais 58 pessoas foram atingidas por E.coli O157:H7, através do consumo de salada [3].

\section{2 - Resistência aos agentes de desinfecção de ver- duras e frutas}

A freqüência de implicação das frutas e vegetais em surtos provocados por E.coli O157:H7 levantou uma série de questões sobre a eficácia dos procedimentos de desinfecção desses produtos e foram realizados muitos trabalhos para avaliar a resistência das cepas de E.coli O157:H7 aos principios ativos mais comuns. Um levantamento geral desses estudos mostra uma variação muito grande nas condições dos ensaios que, além de não relatar acuradamente a metodologia utilizada, não padronizam variáveis importantes como o tipo de desinfetante, a concentração utilizada, o tempo de contato, a temperatura de contato, a forma de preparação do inóculo, a superficie inoculada e a forma de quantificar os sobreviventes, dentre outras.

TAKEUCHI \& FRANK [41], por exemplo, avaliaram o efeito do hipoclorito de sódio (200ppm de cloro residual livre $/ 5 \mathrm{~min} / 22^{\circ} \mathrm{C}$ ) sobre E.coli O $157: \mathrm{H} 7$ inoculada na superficie intacta e em cortes de folhas de alface, observando 0,3 e 0,4 reduções decimais, respectivamente. Os autores relataram uma variação experimental significativa nesse estudo, que atribuirram a diferenças fisiológicas entre as folhas de alface utilizadas nas repetições.

BEUCHAT et al. [7], em estudo similar, obtiveram 0,87 reduções decimais e, segundo TAKEUCHI \& FRANK [41], essa diferença em relação às 0,3 e 0,4 reduções obtidas em seu estudo podem ser atribuidas ao fato de o experimento de BEUCHAT et al. [7] não ter utilizado uma etapa de neutralização do cloro, após o tempo de contato, bem como à variações no nível inicial do inóculo e tempo de contato das folhas com a suspensão contaminante.

BEUCHAT et al.[8] avaliaram o efeito do tratamento de sementes de alfafa com $\mathrm{Ca}[\mathrm{OCl}]_{2}$ (200ppm de cloro residual livre $/ 22^{\circ} \mathrm{C} / 15 \mathrm{~min}$ ) e observaram 1,3 reduções decimais na população de E.coli O157:H7 artificialmente inoculada. Elevando a concentração de cloro residual livre para $20.000 \mathrm{ppm}$, nas mesmas condições, o número de reduções decimais passou para 2,6.

TAORMINA \& BEUCHAT [42] também avaliaram o efeito do tratamento com 20.000ppm de cloro residual 
livre (10min de contato) sobre E.coli O157:H7 artificialmente inoculada em sementes de alfafa e obtiveram resultado similar, com 2,8 reduções decimais. Com $100 \mathrm{ppm}$ de cloro residual livre, nas mesmas condições, obtiveram 2,2 reduções.

Conforme destacado pelos próprios autores, a comparação dos resultados desses trabalhos é complicada e dificulta sobremaneira a conclusão sobre a eficácia dos desinfetantes. Em 2001 BEUCHAT e um grupo de pesquisadores de diversas instituições de pesquisa norteamericanas publicaram um artigo de interesse geral no Journal of Food Protection [6], alertando para a necessidade de padronização de métodos para determinação da eficácia de desinfetantes contra microrganismos patogênicos em frutas e vegetais.

A AOAC dispõe de dois métodos para determinação da atividade bactericida de desinfetantes, adotados oficialmente no Brasil pela PORTARIA 336 de 22 de julho de 1999 [36], da Agência Nacional de Vigilância Sanitária (ANVISA), Ministério da Saúde. São os métodos de diluição de uso e suspensão, cuja principal diferença é a forma como os microrganismos são expostos à ação do desinfetante. No método de diluição de uso as células são fixadas e secadas em um suporte sólido (carreador) e no método de suspensão são suspensas na própria solução desinfetante. As principais vantagens desses métodos em relação à inoculação direta de frutas e vegetais é que todo o procedimento é criteriosamente padronizado, permitindo comparar resultados obtidos em qualquer laboratório do Brasil ou do exterior. O método de suspensão é mais simples, menos trabalhoso e mais barato do que o método de diluição de uso, razão pela qual foi selecionado para a realização desse trabalho, cujos objetivos foram efetuar um levantamento da ocorrência de E.coli O157:H7 em vegetais crus e avaliar sua resistência aos desinfetantes mais amplamente utilizados na desinfecção de verduras e de equipamentos e utensílios de restaurantes e cozinhas industriais.

\section{2 - MATERIAL E MÉTODOS}

\section{1 - Ocorrência em vegetais}

A amostragem foi feita em colaboração com três fornecedores de vegetais do CEASA Campinas (SP), coletando-se cerca de 30 amostras de vegetais por semana, no período de maio a outubro de 1999. Foram selecionadas para o trabalho amostras de alface, rúcula e chicória, que são normalmente consumidos na forma de salada crua. As amostras foram analisadas utilizando-se os "kits" de imunoensaio enzimático da $3 \mathrm{M}$ Company (EHEC Test Kit 3M 6477) ou da Neogem Corporation (Reveal E.coli O157 Test Kit), obedecendo ao seguinte procedimento:

2.1.1 - ELISA 3M (EHEC Test Kit 3M 6477) - 25g da amostra foram homogeneizados com $225 \mathrm{~mL}$ de Caldo EC Modificado Novobiocina ( $\mathrm{mECn}$ ), preparado de acordo com a formulação descrita por OKREND et al. [33]. O caldo foi incubado a $37^{\circ} \mathrm{C}$ por 6 horas sob agitação e, em seguida, transferido para uma incubadora estática por mais 18 horas a $37^{\circ} \mathrm{C}$. Conforme orientação do fabricante, uma aliquota de $1 \mathrm{~mL}$ do caldo enriquecido foi então inoculada em Petrifilm coliformes / E.coli (3M Company) e, após incubação a $41^{\circ} \mathrm{C} / 24 \mathrm{~h}$, foi verificada a presença ou não de colônias típicas de E.coli O157:H7 (colônias glicuronidase negativas, vermelhas, com presença de bolhas de gás). Nos casos em que se observou a presença de colônias típicas foi realizado o imunoensaio enzimático da $3 \mathrm{M}$, seguindo a orientação dos fabricantes. Todas as amostras que apresentaram resultados ELISA positivo foram submetidas à confirmação, estriando-se o caldo de enriquecimento original em placas de Ágar McConkey Sorbitol (Difco 0079). Após incubação a $35^{\circ} \mathrm{C} / 24 \mathrm{~h}$ foram selecionadas colônias típicas (sorbitol negativas, brancas) para confirmação, que foi feita através do teste sorológico de aglutinação em lâmina com o antisoro O157 (Probac do Brasil), atividade de $\beta$-glicuronidase em Caldo Lauril Sulfato Triptose suplementado com 4-metilumbeliferil- $\beta$ D-glicuronídeo (LST-MUG Merck 12588), teste de crescimento em Ágar Tríplice Açúcar Ferro (TSI Difco 0265) e teste de crescimento em Ágar Lisina Ferro (LIA Difco 0849). A partir dos tubos de TSI, as culturas presuntivas foram submetidas à provas bioquimicas adicionais, utilizandose o kit API 20E da BioMerieux.

2.1.2 - ELISA Neogem (Reveal E.coli 0157 Test Kit) - 25g da amostra foram homogeneizados com $225 \mathrm{~mL}$ do Caldo Neogem para E.coli O157 (Reveal media 8 hours 9760) e incubados a $41^{\circ} \mathrm{C}$ por 8 horas sob agitação. O imunoensaio foi realizado com uma alíquota do caldo enriquecido, submetido à fervura, conforme instruções do fabricante. Todas as amostras que apresentaram resultados ELISA positivo foram submetidas à confirmação, estriando-se o caldo de enriquecimento original ( $8 \mathrm{~h}$ de incubação) em placas de Ágar McConkey Sorbitol (Difco 0079). Após incubação a $35^{\circ} \mathrm{C} / 24 \mathrm{~h}$ foram selecionadas colônias típicas para confirmação, que foi feita seguindo o mesmo procedimento utilizado para o método da $3 \mathrm{M}$.

\section{2 - Avaliação da eficácia antimicrobiana de desin- fetantes contra E.coli O157:H7}

O teste de eficácia antimicrobiana foi feito de acordo com o método de suspensão No 960.9 da Association of Official Analytical Chemists [4]. A eficácia foi verificada contra a cepa de E.coli O157:H7 ATCC 43890 e, para comparação, também contra E.coli ATCC 11229 (não patogênica), uma das cepas padrão no Brasil para teste de desinfetantes usados na indústria de alimentos.

$\mathrm{Na}$ realização dos testes foram utilizados os seguintes desinfetantes:

- Solução de hipoclorito de sódio a 100 e $200 \mathrm{mg} / \mathrm{L}$, preparada em água destilada estéril a partir do produto comercial água sanitária Brilhante®. A concentração de cloro residual livre foi determinada por titulação com tiossulfato de sódio, de acordo com técnica descrita por EATON et al. [16].

- Solução de dicloroisocianurato de sódio a 100 e $200 \mathrm{mg} / \mathrm{L}$, preparada em água destilada estéril a partir de produto comercial Aquatabs ${ }^{\circledR}$. A concen- 
tração de cloro residual livre foi determinada conforme descrito anteriormente.

- Solução de cloreto de benzalcônio a 100 e $200 \mathrm{mgL}$, preparada em água destilada estéril a partir do produto comercial "Cloreto de Benzalcônio" P.A. (Vetec Código 1126). A concentração do principio ativo na solução foi determinada de acordo com a metodologia descrita no Manual da Qualidade 65.3210.014 do Instituto Nacional de Controle de Qualidade em Saúde (INCQS) [24].

\section{3 - RESULTADOS E DISCUSSÃO}

\section{1 - Ocorrência em vegetais}

Os resultados da ocorrência de E.coli O157:H7 em vegetais encontram-se sumarizados na Tabela 1. Foram analisadas 869 amostras, das quais 113 (13\%) apresentaram teste presuntivo de ELISA positivo, sendo consideradas suspeitas. Nos testes bioquímicos e sorológicos posteriores, entretanto, a presença do patógeno nessas amostras não foi confirmada, representando uma taxa de falsos presuntivos de $13,6 \%$ nas análises realizadas com o Reveal E.coli O157 da Neogem e 11,8\% das analises realizadas com o EHEC Test Kit da 3M.

TABELA 1. Ocorrência de E.coli O157:H7 em vegetais.

\begin{tabular}{llccc} 
Método & $\begin{array}{c}\text { Tipo de } \\
\text { amostra } \\
\text { analisada }\end{array}$ & $\begin{array}{c}\text { Número de } \\
\text { amostras } \\
\text { analisadas }\end{array}$ & $\begin{array}{c}\text { Número de } \\
\text { amostras suspeitas }\end{array}$ & $\begin{array}{c}\text { Número de } \\
\text { amostras } \\
\text { confirmadas }^{2}\end{array}$ \\
Reveal & Alface & 289 & $43(14,9 \%)$ & 0 \\
E.coli O157 & Chicória & 174 & $13(7,5 \%)$ & 0 \\
Neogem & Rúcula & 101 & $21(20,8 \%)$ & 0 \\
& Total & $\mathbf{5 6 4}$ & $\mathbf{7 7 ( 1 3 . 6 \% )}$ & $\mathbf{0}$ \\
\hline EHEC Test Kit & Alface & 109 & $12(11 \%)$ & 0 \\
3M Company & Chicória & 97 & $11(11,3 \%)$ & 0 \\
& Rúcula & 99 & $13(13,1 \%)$ & 0 \\
& Total & $\mathbf{3 0 5}$ & $\mathbf{3 6}(\mathbf{1 1 . 8 \% )}$ & $\mathbf{0}$ \\
& Total & $\mathbf{8 6 9}$ & $\mathbf{1 1 3 ( 1 3 \% )}$ & $\mathbf{0}$
\end{tabular}

${ }^{1}$ Amostras que apresentaram teste de ELISA positivo. ${ }^{2}$ Amostras nas quais a presença de E.colic
sorologicas e bioquimicas tradicionais.

É importante destacar que a base de dados do API $20 \mathrm{E}$ não diferencia as cepas $\mathrm{O} 157$ das demais cepas de E.coli, tendo sido utilizada, na interpretação dos resultados, a orientação de HALDANE et al. [22], segundo a qual a combinação mais típica dessas cepas nos 21 primeiros testes da cartela de resultados do API 20E (Figura 1) é "5144172" (91,9\% das cepas), podendo também ocorrer as combinações "5144152" (cepas sacarose negativas, $2,7 \%$ ) e "5144162" (cepas ramnose negativas, $5,4 \%)$.

Levantamentos sobre a ocorrência de E.coli O157:H7 em alimentos são raramente encontrados na literatura, sendo mais comuns os relatos diretamente relacionados com surtos. Segundo KNIGHT [26] pesquisas em supermercados americanos revelaram E.coli O157:H7 em 1 a $2,5 \%$ das amostras de carne testadas (bovina, suina e de aves) e um levantamento realizado no México revelou contaminação em $19 \%$ dos vegetais analisados [5]. Numa compilação apresentada por DESMARCHELIER \& GRAU
[15], relatos de diferentes partes do mundo indicaram contaminação em $0,2 \%$ das carcaças de bovinos analisadas, 0 a $3,7 \%$ da carne bovina moída, 0 a $1,5 \%$ da carne de porco, $2 \%$ da carne de carneiro e 0 a $1,5 \%$ da carne de aves.

\begin{tabular}{|c|c|c|c|c|c|c|c|}
\hline$+\quad+$ & + & $-\quad+$ & - & & + & +++ & $-\quad+$ \\
\hline 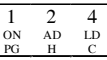 & $\begin{array}{ccc}1 & 2 & 4 \\
O \mathrm{OD} & \mathrm{CIT} & \mathrm{H}, \mathrm{S} \\
\mathrm{C} & \end{array}$ & $\begin{array}{ccc}\begin{array}{ccc}1 \\
\mathrm{UR} \\
\mathrm{E}\end{array} & \underset{\mathrm{TD}}{\mathrm{TD}} & 4 \\
\mathrm{~A} & \mathrm{IND} \\
\end{array}$ & $\begin{array}{ll}1 & 2 \\
\mathrm{VP} & \mathrm{GE} \\
& \mathrm{L} \\
\end{array}$ & & \begin{tabular}{|ll}
1 & 2 \\
MA & \\
$N$ & INO \\
$N$
\end{tabular} & 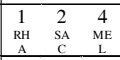 & $\begin{array}{|ccc|}1 & 2 & 4 \\
\mathrm{AM} & \mathrm{AR} & \mathrm{OXX} \\
\mathrm{Y} & \mathrm{A} & \mathrm{OX} \\
\end{array}$ \\
\hline 5 & 1 & 4 & 4 & & 1 & 7 & 2 \\
\hline
\end{tabular}

FIGURA 1. Características típicas das cepas de E.coli O157:H7 no "Kit"API 20E da BioMérieux [22].

ONPG $=$ orto-nitro-fenil- $\beta$-D-galactopiranosídeo (atividade de $\beta$-galactosidase), ADH $=$ atividade de arginina dehidrolase, $\mathrm{LDC}=$ atividade de lisina descarboxilase, $\mathrm{ODC}=$ atividade de ornitina descarboxilase, $\mathrm{CIT}=$ utilização de ciitrato, $\mathrm{H}_{2} \mathrm{~S}=$ produção de $\mathrm{H}_{2} \mathrm{~S}$, URE $=$ atividade de urease, TDA = atividade de triptofano deaminase, IND = produção de indol, VP $=$ produção de acetoina (teste de VP), GEL = atividade de
gelatinase, GLU $=$ fermentação/oxidação da glicose MAN $=$ fermentação/oxidação gelatinase, $\mathrm{GLU}=$ fermentação/oxidação da glicose, $\mathrm{MAN}=$ fermentação/oxidaçãão
do manitol, $\mathrm{INO}=$ fermentação/oxidaão do inositol, $\mathrm{SOR}=$ fermentaça/oxidação do sorbitol, RHA = fermentação/oxidação da rhamnose, SAC = fermentação/oxidação da sacarose, MEL = fermentação/oxidação da melibiose, AMY = fermentação/ oxidação da amigdalina, ARA = fermentação/oxidação da arabinose, OX = atividade de citocromo oxidase. Os números que acompanham o teste são os pontos a serem atribuídos quando o resultado for positivo, para compor a combinação numérica.

No Brasil não há dados sistemáticos que possam indicar a situação da ocorrência de E.coli O157:H7 em alimentos. SILVEIRA et al. ([40] analisaram cerca de 800 amostras de hambúrgueres produzidos por frigoríficos do sul e sudeste, não sendo detectada a presença de E.coli O157:H7 nas amostras. Em levantamento similar, SILVA et al. [39] analisaram 340 amostras de produtos cárneos e ambiente industrial, também não sendo detectada a presença desse microrganismo. Esses resultados, assim como os obtidos em nosso trabalho, revelam uma baixa freqüência desse patógeno em nossos produtos, considerando-se que amostragens similares em outros países têm detectado a presença, em porcentagens variadas das amostras analisadas. Ainda assim, devem ser interpretados cuidadosamente: em primeiro lugar, assim como todos os dados de amostragem, não devem ser entendidos como garantia de ausência porque, ainda que o tamanho das amostras seja da mesma ordem de grandeza encontrada em levantamentos similares fora do Brasil, está muito longe do tamanho da produção do país. Em segundo lugar, a qualidade microbiológica dos vegetais varia muito de região para região, sendo afetada pelas condições de cultivo, tratamento da água de irrigação, tratamento de esgotos e sistema de distribuição. Em nosso trabalho a amostragem foi feita apenas na cidade de Campinas, onde os vegetais apresentam, segundo dados de NASCIMENTO [31], boa qualidade sanitária e baixa contaminação por coliformes fecais, E.coli e Salmonella.

Além disso, o Centro de Vigilância Epidemiológica do Estado de São Paulo (CVE/SP) [14] registrou, no período de 1998 a 2000, 15 casos de HUS em hospitais públicos do Estado, com histórico anterior de diarréia e possivel associação com E.coli O157:H7. Nos casos em que foi feita a coprocultura a presença de E.coli foi detectada mas o agente não foi isolado e/ou sorotipado para confirmação. Também no Rio Grande do Sul, um estudo retrospectivo de casos de HUS ocorridos no Hospital Universitário da Universidade Federal de Santa 
Maria, no periodo de março de 1997 a agosto de 1999, apontou a existência de 31 casos da doença em crianças com idade de 2 a 57 meses [14]. Esses relatos atestam a existência de HUS no país e deixam clara a necessidade de monitoramento dessa bactéria em diferentes produtos e regiões, porque a experiência tem demonstrado que, num mercado globalizado, patógenos emergentes podem ser rapidamente disseminados pelo mundo, considerando-se a intensa movimentação internacional de pessoas e mercadorias. O CVE já implantou um sistema de vigilância ativa no Estado de São Paulo e, considerando-se que a maioria dos surtos relatados na literatura internacional foram veiculados por alimentos, é de grande interesse para a saúde pública que estudos de ocorrência continuem a ser efetuados em todas as regiões do país.

\subsection{Resistência aos sanitizantes}

Os resultados dos testes de resistência de E.coli O157:H7 (ATCC 43890) e E.coli comum (ATCC 11229) aos sanitizantes encontram-se sumariados na Tabela 2.

O método utilizado nas análises (teste de suspensão AOAC 960.9) preconiza como eficaz, na concentração testada, os sanitizantes que apresentarem 5 ou mais reduções decimais na população alvo, após 30 segundos de contato. De acordo com esse critério, todos os desinfetantes testados se mostraram eficazes contra E.coli O157:H7, nas concentrações de 100 e 200ppm. Esses resultados concordaram com os obtidos contra E.coli ATCC 11229 (cepa padrão recomendada pela AOAC para testes de eficácia antimicrobiana de desinfetantes de uso na indústria de alimentos), demonstrando que, nos testes realizados, as duas cepas apresentaram comportamento equivalente quanto á resistência a esses agentes de desinfecção. Esse resultado é importante para os profissionais responsáveis pelo controle de qualidade em restaurantes e cozinhas industriais, porque a análise de coliformes fecais e E.coli é relativamente simples e comum nos laboratórios das empresas, o que não acontece com a análise de E.coli O157:H7.

CHESCA [12] realizou um estudo comparativo da eficácia antimicrobiana de diversos desinfetantes contra as mesmas cepas de E.coli O157:H7 ATCC 43890 e E.coli comum ATCC 11229, artificialmente inoculadas em amostras de alface, observando que o tratamento com 200 ppm de hipoclorito de sódio/15min promoveu uma média de 4,09 reduções decimais na população de E.coli comum e 2,70 reduções decimais na população de E.coli O157:H7. O tratamento com 200ppm de dicloroisocianurato de sódio/15min promoveu uma média de 3,69 reduções decimais na população de E.coli comum e 2,57 reduções decimais na população de E.coli O157:H7. A análise estatística não evidenciou diferença significativa entre os resultados obtidos contra E.coli O157:H7 e E.coli comum, comprovando que as duas cepas apresentaram resistência semelhante aos tratamentos de desinfecção com compostos de cloro. Por outro lado, esses valores de redução decimal são menores do que os obtidos em nosso trabalho, variação provavelmente devida à diferença na forma de exposição das cé- lulas ao desinfetante, em suspensão, no nosso caso e fixadas às folhas de alface, no caso de CHESCA.

TABELA 2. Resultados dos testes de resistência de E.coli O157:H7 aos sanitizantes empregando-se o método AOAC 960.9.

\begin{tabular}{|c|c|c|c|c|c|c|c|}
\hline \multirow{3}{*}{ Desinfetante } & \multirow{3}{*}{$\begin{array}{c}\text { Concentração e } \\
\text { tempo de } \\
\text { contato }\end{array}$} & \multicolumn{6}{|c|}{ Contagem inicial, final e número de reduções decimais * } \\
\hline & & \multicolumn{3}{|c|}{$\begin{array}{l}\text { E. coli O157:H7 ATCC } 43890 \\
(\log \text { UFC/mL) }\end{array}$} & \multicolumn{3}{|c|}{$\begin{array}{l}\text { E.coli ATCC } 11229 \\
\quad(\log \text { UFC/mL })\end{array}$} \\
\hline & & Inicial & Final & Reduções* & Inicial & Final & Reduções" \\
\hline \multirow{2}{*}{$\begin{array}{l}\text { Dicloroisocianurato } \\
\text { de sódio }\end{array}$} & $100 \mathrm{ppm} / 30 \mathrm{~s}$ & 9,1 & $<3,0$ & $>6,1$ & 8,8 & $<3,0$ & $>5,8$ \\
\hline & $200 \mathrm{ppm} / 30 \mathrm{~s}$ & 9,3 & $<3,0$ & $>6,3$ & 9,6 & $<3,0$ & $>6,6$ \\
\hline \multirow{4}{*}{$\begin{array}{l}\text { Hipoclorito } \\
\text { de sódio }\end{array}$} & $100 \mathrm{ppm} / 30 \mathrm{~s}$ & 9,3 & $<3,0$ & $>6,3$ & 9,7 & $<3,0$ & $>6,7$ \\
\hline & & 9,4 & $<3,0$ & $>6,4$ & 9,7 & $<3,0$ & $>6,7$ \\
\hline & $200 \mathrm{ppm} / 30 \mathrm{~s}$ & 9,3 & $<3,0$ & $>6,3$ & 9,7 & $<3,0$ & $>6,7$ \\
\hline & & 9,4 & $<3,0$ & $>6,4$ & 9,7 & $<3,0$ & $>6,7$ \\
\hline \multirow{4}{*}{$\begin{array}{l}\text { Cloreto de } \\
\text { benzalcônio }\end{array}$} & $100 \mathrm{ppm} / 30 \mathrm{~s}$ & 9,3 & 3,8 & 5,5 & 9,6 & $<3,0$ & $>6,6$ \\
\hline & & 9,7 & 3,9 & 5,8 & 9,7 & $<3,0$ & $>6,7$ \\
\hline & $200 \mathrm{ppm} / 30 \mathrm{~s}$ & 8,3 & $<3,0$ & $>5,3$ & 7,9 & 2,0 & 5,9 \\
\hline & & 9,7 & $<3,0$ & $>6,7$ & 9,7 & $<3,0$ & $>6,7$ \\
\hline
\end{tabular}

* O número de reduções decimais é definido como [Log UFC da população inicial Log UFC da população final].

É importante considerar, na interpretação de resultados obtidos pelo método de suspensão AOAC 960.0, as vantagens e as limitações da técnica. A principal vantagem é que o método é padronizado e reconhecido internacionalmente, de forma que os dados podem ser comparados, permitindo verificar se as cepas avaliadas apresentam diferença na resistência aos desinfetantes testados. A principal desvantagem é que o método não reproduz as condições de adesão e formação de biofilmes que se observa na prática de desinfecção de vegetais. Nessas condições, os resultados da literatura deixam claro que a eficácia dos desinfetantes, aplicados tanto à microbiota natural quanto à cepas de microrganismos artificialmente inoculadas em superficies de frutas e verduras, é muito menor do que nos testes de suspensão. Além disso, mesmo que a característica de resistência das cepas aos diferentes principios ativos dos desinfetantes seja similar, as diferenças nas características de adesividade e formação de biofilmes podem interferir na eficácia dos desinfetantes $[1,13,20,23,27,29,35,37,45]$

Outro fator importante a considerar é o fato de desinfetantes com o mesmo princípio ativo, porém, de marcas comerciais distintas, apresentarem diferença na eficácia antimicrobiana [17]. Assim, é imprescindivel o monitoramento periódico da qualidade dos produtos disponiveis no mercado, para garantir segurança dos tratamentos de desinfecção aplicados.

Considerando-se ainda a crescente participação dos vegetais na transmissão de E.coli O157:H7 e as evidências de que, no Brasil, casos de HUS podem estar sendo veiculados por alimentos, é importante que sejam conduzidos novos estudos para avaliar a resistência de outras cepas de E.coli O157:H7 aos diferentes desinfetantes disponiveis no mercado. Ainda mais importante é que esses estudos sejam conduzidos com métodos padronizados, que reproduzam as condições experimentais, de 
forma que os resultados possam ser comparados e utilizados na tomada de decisões pelos agentes de saúde e controle de qualidade.

\section{4 - CONCLUSÕES}

Não foi detectada a presença de E.coli O157:H7 nas amostras de vegetais analisadas, corroborando resultados já obtidos para produtos cárneos no Brasil por SILVEIRA [40] e SILVA [39]. Embora esses resultados não possam ser interpretados como garantia de ausência desse patógeno no país, atesta que a ocorrência em nosso meio é, certamente, mais baixa do que em outros países.

Nosso estudo demonstrou que tanto o cloreto de benzalcônio quanto o hipoclorito e o dicloroisocianurato de sódio são eficazes na destruição de E.coli O157:H7 em suspensão, nas concentrações de 100 e 200ppm, após 30s de contato. Demonstrou também que a resistência da cepa de E.coli O157:H7 ATCC 43890 a esses desinfetante é similar à resistência da cepa padrão AOAC para ensaios de eficácia antimicrobiana, E.coli ATCC 11229. Assim, é razoável supor que, no monitoramento dos processos de desinfecção de verduras em restaurantes e cozinhas industriais, acompanhar a redução na contagem de E.coli ou coliformes fecais depois da desinfecção seja suficiente para avaliar a segurança dos tratamentos.

\section{5 - REFERÊNCIAS}

[1] ANDRADE, N. J., BRIDGEMAN, T. A., ZOTTOLA, E. A., Bacteriocidal activity of sanitizers against Enterococcus faecium attached to stainless steel as determined by plate count and impedance methods. J. Food Prot., v. 61, n. 7, p. 833-838, 1998.

[2] ANÔNIMO. Verocytotoxin-producing Escherichia coli (enterohemorrhagic E.coli) infections, Japan, 1996-June 1997. http://idsc.nih.go.jp/iasr/18/209/ tpc209.html, 2001.

[3] ANÔNIMO. About E.coli - history, prevention, symptoms \& risks, recent outbreaks. http://www.about-ecoli.com, 2001.

[4] BELOIAN, A. (Ed). Disinfectants. AOAC Official Method 960.09. In: Association Of Official Analytical Chemists. Official methods of analysis of the Association Of Official Analytical Chemists. 16 ed., Gaithersburg, Maryland: 1998, v. I, Chap. 6, p. 9-11.

[5] BEUCHAT, L.R. Pathogenic microorganisms associated with fresh produce. Journal of Food Protection, v.59, n.2, p.204-216, 1996.

[6] BEUCHAT, L.R., FARBER, J.M., GARRETT, E.H. et al. Standardization of a method to determine the efficacy of sanitizers in inativating human pathogenic microrganisms on raw fruits and vegetables. Journal of Food Protection, v.64, n.7, p.1079-1084, 2001.

[7] BEUCHAT, L.R., NAIL, B.V., ADLER, B.B. \& CLAVER, M.R.S. Efficacy of spray application of chlorinater water in hilling pathogenic bacteria on raw apples, tomatoes, and lettuce. Journal of Food Protection, v.61, n.10, p.1305-1311, 1998.

[8] Beuchat, L.R., WARD, T.E. \& PETTIGREW, C.A. Comaprison of chlorine and a prototype produce wash product for effectiveness in killing Salmonella and Escherichia coli O157:H7 on alfafa seeds. Journal of Food Protection, v.64, n.2, p.152-158, 2001.

[9] CDC. Outbreak of Escherichia coli O157:H7 infections associated with drinking unpasteurized commercial apple juice - Britsh Columbia, California, Colorado and Washington, October 1996. Morbidity and Mortality Weekly Report, v.45, n.44, p.975, November 1996.

[10] CDC. Outbreaks of Escherichia coli O 157:H7 infections and cryptosporidiosis associated with drinking unpasteurized apple cider - Connecticut and New York, October 1996. Morbidity and Mortality Weekly Report, v.46, n.01,.p48, January 1997.

[11] CDC. Outbreak of Escherichia coli O157:H7 infections associated with eating alfafa sprouts - Michigan and Virginia, June-July 1997. Morbidity and Mortality Weekly Report, v.46, n.32, p.741-744, August 1997.

[12] CHESCA, A.C. Eficácia de Diferentes Sanitizantes na Desinfecção de Alface (Lactuca sativa) Artificialmente Inoculadas. 2002. Tese de doutorado, Departamento de Produção Vegetal, Faculdade de Ciências Agrárias e Veterinárias/UNESP Campus Jaboticabal.

[13] CosTA, E. T. R. Desenvolvimento de metodologia para detecção da adesão microbiana em superficie inoxidável. Rio de Janeiro, 1999. 81f. Dissertação (Mestrado em Microbiologia Veterinária) - Universidade Rural do Rio de Janeiro.

[14] CVE/SP. Informe-Net DTA -Doenças transmitidas por alimentos. Centro de Vigilância Epidemiológica, Secretaria de Saúde do Estado de São Paulo, 2001. Disponível no site http://www.cve.saude.sp.gov.br/htm/ dta_menu.htm

[15] DESMARCHELIER, P.M. \& GRAU, F.H. Escherichia coli. In: HOCKING, A.D., ARNOLD, G., JNSON, I. et al.eds. Foodborne Microrganisms of Public Health Significance. Sydney, Australia: Australian Institute of Food Science and Technology Inc., Chapter 7, p.231264, 1997.

[16] EATON, A.D., CLESCERI, L.S., GREENBERG, A.E.(eds.). Standard Methods for the Examination of Water and Wastewater. 19 $^{\text {th }}$ ed. Washington: American Public Health Association (A.P.H.A.), American Water Works Association (A.W.W.A.), Water Environment Federation (W.E.F.), 1995.

[17] EIROA, M.N.U. \& PORTO, E.. Evaluation of different chlorine based disinfectants and vinegar against Vibrio cholerae present in lettuce. Colet.ITAL,, v.25,n.2, p.169-172, 1995.

[18] FDA/CFSAN. Escherichia coli O157:H7. In: Food and Drug Administration, Center for Food safety \& Applied Nutrition, Foodborne Pathogenic Microrganisms and Natural Toxins Handbook (The "Bad Bug Book"), Chap.15, 2001. Disponivel no site http:// vm.cfsan.fda.gov/ mow/badbug.zip.

[19] FENG, P. Escherichia coli serotype O157:H7: Novel vehicles of infections and emergence of phenotypic variantes. Emerging Infectious Diseases, v.1, n.2, p.1-9, 1995. Disponivel no site http://www.cfsan.fda.gov/ mow/ feng.htm.

[20] FRANK, J. H.; KOFI, R. A surface-adherent growth of Listeria monocytogenes is associated with resistance to surfactant sanitiers and heat. J. Food Prot., Georgia, v. 53, n. 7, p. 550-554, 2000.

[21] GRIFFIN, P.M. \& TAUXE, R.V. The epidemiology of infections caused by Escherichia coli O157:H7, other 
enterhemorrhagic E.coli, and the associated Hemolityc Uremic Syndrome. Epidemiologic Reviews, v. 13, p.6098, 1991.

[22] HALDANE, D.J.M., DAMM, M.A.S., ANDERSON, J.D. Improved biochemical screening-procedure for small clinical laboratories for vero (shiga-like)-toxin-producing strains of Escherichia coli O157-H7. Journal of Clinical Microbiology, v.24, n. 4, p.652-653, 1986.

[23] HOOD, S. K.; ZOTTOLA, E. A. Growth media and surface conditioning influence the adherence of Pseudomonas fragi, Salmonella typhimurium and Listeria monocytogenes cells to stainless steel. J. Food Prot., Georgia, v. 60, n. 9, p. 1034-1037, 1997.

[24] INCQS, 1999. Determinação de tensoativo aniônico e catiônico. Manual da Qualidade 65.3210.014. Rio de Janeiro: Instituto Nacional de Controle de Qualidade em Saúde.

[25] KARMALI, M.A. Infections by verocytotoxin-producing Escherichia coli. Clinical Microbioly Reviews, v.2, p.1538, 1989.

[26] KNIGHT, P. Hemorragic Escherichia coli: the danger increases. ASM News v.59,n.5,p.247-250, 1993.

[27] LeCheVAlier, M. W.; BABCOCK, T. M.; LEE, R. G. Examination and characterization of distribution system biofilms. Appl. and Environmental Microbiology., Washington, v. 53, n. 12, p. 2714-2724, 1987.

[28] MARCH, S.B.; RATNAM, S. Sorbitol MacConkey Medium for detection of Escherichia coli O157:H7 associated with haemorragic colits. Journal of Clinical Microbiology, v.23, p. 869-872, 1986.

[29] MOSTELLER, T. M., BISHOP, J. R., Sanitizer efficacy against attached bacteria in a milk biofilm. J. Food Prot., v. 56, n. 1, p. 34-41, 1993.

[30] MENG , J.; DOYLE, M.P.; ZHAO, T. et al. Detection and control of Escherichia coli O157:H7 in foods. Trends in food Science \& Technology, v. 51,p.179-184, 1994.

[31] NASCIMENTO, M.S. Avaliação comparativa de tratamentos químicos na sanitização de frutas e verduras. 2002. Dissertação de Mestrado, Faculdade de Ciências Farmacêuticas/UNESP Câmpus de Araraquara.

[32] OKREND, A.J.G.; ROSE, B.E.; BENNET, B. A. screening method for the isolation of Escherichia coli O157:H7 from ground beef. Journal of Food Protection ,v.53, p. 249252, 1990a.

[33] OKREND, A.J.G.; ROSE, B.E.; MATNER, R. An improved . screening method for the detection and isolation of Escherichia coli O157:H7 from meat, incorporating the 3M Petrifilm Test Kit - HEC for hemorragic Escherichia coli O157:H7. Journal of Food Protection, v.53, p. 936940, 1990b.

[34] OLSEn, S.J., MacKinOn, L.C., GOULDING, J.S. et al. Surveillance for foodborne disease outbreaks - United States, 1993-1997. Morbidity and Mortality Weekly Report, v.49, n.SS01, p.1-51, March 17, 2000.
[35] PARIZZI, S. Q. F. Adesão bacteriana em superfície de serviços de alimentação hospitalar avaliação microscopia de epifluorescência. 1998. 57 f. Dissertação (Mestrado em Ciências Tecnologia de Alimentos) - Universidade Federal de Viçosa, Viçosa.

[36] PORTARIA 336/99 ANVS/MS. Regulamenta o Registro de Produtos Saneantes Domissanitários e Afins, de Uso Domiciliar, Institucional e profissional. Brasília: Agência Nacional de Vigilância Sanitária, Ministério da Saúde, 22 de julho de 1999. Publicada no D.0.U. 30/07/ 99, Seção 1.

[37] RONNER, A. B.; WONG, A. C. L. Biofilm development and sanitizer inactivation of Listeria monocytogenes and Salmonella typhimurium on stainless stell and buna-n rubber. J. Food. Prot., Gerogia, v. 56, n. 9, p. 750-758, 1993.

[38] SHUTERLAND, J.P.; BAYLISS, A.J.; BRAXTON, D.S. Predictive modelling of growth of Escherichia coli O157:H7:the effects of temperature, $\mathrm{pH}$ and sodium chloride. International Journal of Food Microbiology, v.25, p. 29-49, 1995.

[39] SILVA, N., SILVEIRA, N.F., CONTRERAS, C., et al. Ocorrência de Escherichia coli O157:H7 em produtos cárneos no Brasil. Ciênc. Tecnol. Aliment., v.21, n.2, p.223227, 2001.

[40] SILVEIRA, N.F., SILVA, N., CONTRERAS, C. et al. Occurrence of Escherichia coli O157:H7 in hamburgers produced in Brasil. J.Food Protection, v.62, n.11, p.1333-1335, 1999.

[41] TAKEUCHI, K. \& FRANK, JF. Quantitative determination of the role of lettuce leaf structures in protecting Escherichia coli O 157:H7 from chlorine disinfection. Journal of Food Protection, v.64, n.2, p.147-151, 2001.

[42] TAORMINA, P.J. BEUCHAT, L.R. Comparison of chemical treatments to eliminate enterohemorragic Escherichia coli O 157:H7 on alfafa seeds. Journal of Food Protection, v.62, n.4, p.318-324, 1999.

[43] USDA, 1994. Escherichia coli O157:H7: issues and ramifications. United States Department of Agriculture, Center for Epidemiology and Animal Health, Colorado, USA, March 1994, 48p.

[44] WEAGANT, S.D.; BRYANT, J.L.; JINNEMN, K.G. An improved rapid technique for isolation of Escherichia coli O157:H7 from foods. Journal of Food Protection, v. 58,n. 1, p. 7-12, 1995.

[45] WIRTANEN, G.; HUSMARK, U.; MATTILA-SANDHOLM, T. Microbial evaluation of the biotransfer potencial from surfaces with Bacillus biofilms after rinsing and cleaning procedures in closed food-processing systems. J. Food Prot., Georgia, v. 59, n. 7, p. 727-733, 1996.

\section{6 - AGRADECIMENTOS}

Agradecemos à Fundação de Amparo à Pesquisa do Estado de São Paulo (FAPESP) pelo financiamento do trabalho. 